\title{
Key Performance Indicators (KPIs) Impacts in Project Management Albuoul BZ*
}

Department of Engineering, Master of Construction Project Management, Anglia Ruskin University, UK

*Corresponding author: Albuoul BZ, Department of Engineering, Master of Construction Project Management, Anglia Ruskin University, UK, Tel: +448452713333; Email: bob1000bob@yahoo.com

Received date: July 07, 2017; Accepted date: September 07, 2017; Published date: September 14, 2017

Copyright: ( 2017 Albuoul BZ. This is an open-access article distributed under the terms of the Creative Commons Attribution License, which permits unrestricted use, distribution, and reproduction in any medium, provided the original author and source are credited.

\section{Abstract}

As regards to project success, there are Key Performance Indicators (KPIs) should be involved in the project management process, KPIs are organizational based. They have quantitative metric value and basically should be presented in term of management dashboard and be adopted by projects managers.

Keywords: Management; Budget; Capital; Legislation; Revenue

\section{Time Schedule}

Running a project and predict its completion date is major challenge. Since there are a lot of factors affecting time table of the project. Hours used vs. Hours estimated vs. Hours remaining one of the KPIs that determine if the project on track and will be completed at the deadline as expected or there will be any delay. On the other hand, and more specifically, there is an expression of: average time tasks stay in each stage, which determine the exact time needed to complete each stage solely. As an outcome these terms helps the project manager to detect any delay and rapidly find solutions and backup plan to fix and run the project again without any problems. Another related concept called as cycle time and it is two types; project cycle and process cycle. This concept in general describes the whole project time, since its beginning until completion date. Its equation based on the shorter the cycle times, the faster the investment is returned to the organization, it is critical to be aware whether you are acting as a time keeper. As a project manager it is critical point in the way of gaining trust from other customers and builds a good reputation to deliver all work on time and getting all assignments done before their deadlines [1].

\section{Productivity Performance}

Productivity is an essential issue to be considered when running a project, it can be defined as the measurement across the organization determined by the revenue per employee to this organization. In another way it can gives directions whether you are getting your money worthy from your employees and other inputs in this organization. The right way to determine the productivity measure is to ask what is the output being measured. Productivity also assessed through the ratio between output to input, it is basically measured by the effectiveness and efficiency of the organization in generating output via utilizing the available resource. A concept of profitability which means the median profit on turnover percentage or can be defined as the accomplishment of satisfactory level of profits which indeed, very important for the expansion and prosperity for firms and organizations. Resource available usage and utilization is the key, maximize the ability to use our resources and minimize any wasting method will obviously enhance the productivity and the profitability respectively [2]. Well, as seen and can be prophesy; productivity getting affected by many factors as any other KPI since they all acting together and cannot be isolated. Time needed, cost as well as supply chain deliver as will be discussed later on, are all factors increase or decrease productivity depending. As a project manager the valuable outcome is the criterion to determine the effectiveness of the productivity performance and determine whether its worthy or not! Hence, attention and being accurate in determining the improvement and the value added since the inputs toward outputs. Resource maximum utilization is mandatory, and should be the intent of all team members.

\section{Budget}

Budgeting, indeed, without equity capital there is no way to start planning and get the work done. Balanced budget is the main goal to be achieved throughout the whole process. Budgeting best definition ensures balanced cost estimation between revenue and expenses over a period of time with continuing re-evaluation. It is the work engine for any project, exact possible estimation is required and proper documentation ensure in somehow, proper spending and reduce squandering. A concept of return on investment (ROI) should be clarified since it gives us a clear understanding to evaluate the project investment. This formula of ROI provides us a percentage return for every paid coin we have invested. ROI can be calculated via: net benefits/costs $\times 100 \%$. And according to the project type we can mention the sources of returns, such as: increased quantity of output, thrift costs. And outlays such as: resources costs, designing, travelling costs. As project manager it is crucial point not to be labelled as "debtor". Line items that presented in budgeting draft provides more detailed way to see how the budget was spent. Regarding Marr et al. [3] emphasize that we have to find out the best way to manage and reduce costs via charting and analysing all of the revenue and expenses.

\section{Quality}

Quality it is one of the most important KPIs that responsible mainly about customer's satisfaction issues whether it was a product or a service. Providing high quality materials or services considered as the best and quickest way to gain your customer's trust. The known easiest key to success for every project is to achieve the highest possible quality with the lowest cost utilizing the available resources. The best indicators for quality as many researches assured is the customer's satisfaction. Ongoing quality assessment methods should be adopted. If there were any quality defect; reassessment and re-evaluating, 
auditing processes might be starts which counted also one of the quality standers. Total quality management (TQM) one of the vital concepts in this Field. Quality assurance (QA) and quality function deployment (QFD) and many other concepts related to quality measurements techniques are presented and elaborated [4].

As a project manager quality indicator should always have adopted, assessed and evaluate. Surveys are one of the well-known method to assess customer's satisfaction and could be used every once awhile to measure and determine this related level of customer's satisfactions for the products or for the services provided.

\section{Health and Safety}

Health and safety occupies remarkable status when it's come to KPIs for a project. This indicator is essential for running a project not treated as extra or luxury indicator. It can be performed through workplace related items, such as: waste recycling, minimizing the use of energy, used the least harming products to the environment and following global safety measurements and keeps update through activating related programmes for the team members.

Therefore, employment insurance that covers work related injuries or any health problems should be insured. Legislations and specialized polices should be made and adopted by stakeholders to guarantee safe work flow [5]. It is vital issues that cannot be ignored or released, especially when it's come for the global recent legislation and standards for health and safety. As a project manager it is one of the priority list to keep healthy and safety work environment. In the end it will for sure, decrease and relieve a lot of burdens and lots of possible risks, whether they were financial or emotional or even legal issues related.

\section{Waste Management}

Among different projects type, the matter of waste management occupies valuable space, and it is counted one of the hot subjects to be discussed globally in relations to projects in their end stages, when wastes start to appears with poor management regarding. Waste can be best defined as the materials that are no longer needed for its primary goals within the project and they can be classified for many types: solid, liquid, hazardous, non-hazardous. Effective waste management lead to satisfactory result and this can be reached through utilizing polices related, such as universally known Waste Management Plan (WMP). In relation, there is a concept of 4 Rs which stands for Reduce, Reuse, Recycle and Reclaim respectively. This 4Rs concept gives the project manager a hint to be aware about the projects related waste degree and how to be treated with minimum level of environment pollution [6]. As a project manager, planning for waste management is the same level of importance as other related project items from the beginning of running the project.

\section{Supply Chain Deliver Management}

Effective supply chain deliver management has become universally a valuable method to improve and develop the organization performance. It can be defined as sophisticated system of workers, information and activities that responsible to deliver and transport the end product or services to the end customers and it is consisting of two or more of legal organizations. For healthy supply chain management, you as a project manager need to make sure that the following four factors are presented in the process correctly: (1) Storage place utilization which related to the capacity of the storage over a period of time. This point can help project manager to decide if they have to change this storage or not, whether because of the size or place. (2) Order to fill which define as the rate of orders that can be filled based on stocks available. This rate is helpful to determine the stocks balance and predicting the amount of sales. (3) On time delivery, which considered as a way to predict the suspected arrival time of orders to the costumors. (4) Perfect order metric, it is dynamic factor and treated as the key to achieve the high level of the whole process performance $[7,8]$ (Figure 1).

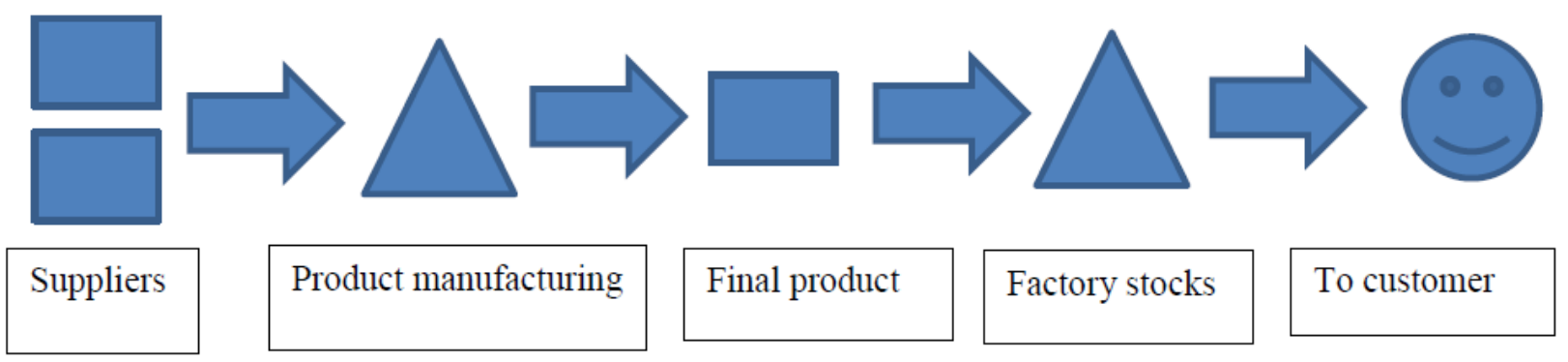

Figure 1: Example of Supply chain.

\section{Conclusion}

In summary, the value of the project flourishing through persistence, hard working with good commands of manager who has developed the leadership characteristics and acting upon them with cohesive collaborated teamwork. Utilizing the previously discussed most common KPIs that could be related to any project planned to be run as mentioned in most of the related books and journals, this all will show and exhibit a perfect view for a successful project management. KPIs have a strong relationship between each other and they should be treated as one package. Prioritizing them always should be organizational base and regarding the manager point of view at that time, giving that there are always urgent and unexpected circumstances that might change the priority at certain point of time. Project manager indeed, should represent the characteristics of leader and leadership with the character of manager as well.

\section{References}

1. Fleming QW, Koppelman JM (2016) Earned value project management. 
Citation: Albuoul BZ (2017) Key Performance Indicators (KPIs) Impacts in Project Management. Bus Eco J 8: 316. doi:

2. Schreyer P (2001) The OECD productivity manual: a guide to the measurement of industry-level and aggregate productivity. International Productivity Monitor 2: 37-51.

3. Marr B, Schiuma G, Neely A (2004) Intellectual capital-defining key performance indicators for organizational knowledge assets. Business Process Management Journal 10: 551-569.

4. Chin L, Khee Poh L (1999) Implementing quality in property management-The case of Singapore. Property management, 17: 310-320.

5. Robson LS, Clarke JA, Cullen K, Bielecky A, Severin C et al., (2005) The effectiveness of occupational health and safety management system interventions: a systematic review. Safety Science 45: 329-353.
6. Franzson H, Helgadóttir HM, Öskarsson F (2015) Surface Exploration and First Conceptual Model of the Dallol Geothermal Area, Northern Afar, Ethiopia. In Proceedings of the World Geothermal Congress, Melbourne, Australia, pp: 19-25.

7. Stadtler H, Kilger C (2002) Supply chain management and advanced planning.

8. Cleland DI (1998) Field guide to project management. Van Nostrand Reinhold, pp: 3-33. 